\title{
Leitura e escrita femininas no século XIX*
}

\author{
Mônica Yumi Jinzenji**
}

\section{Resumo}

Esta pesquisa analisa as práticas de leitura e escrita realizadas por mulheres na primeira metade do século XIX. Trata-se de um período em que o domínio das habilidades de leitura e escrita no Brasil era restrito a uma pequena parcela da população, existindo poucos indícios dessas práticas relacionadas ao universo feminino. Foram analisados periódicos em circulação no período, entre eles O Mentor das Brasileiras (São João del-Rei/MG, 1829-1832), em que estão presentes textos de autoria feminina e referências às práticas de leitura de mulheres.

Palavras-chave: Gênero, Práticas de Leitura, Imprensa Periódica, Século XIX.

" Recebido para publicação em 09 de abril de 2010, aceito em 20 de junho de 2011.

** Professora Adjunta da Faculdade de Educação da UFMG. monicayj@ufmg.br

cadernos pagu (38), janeiro-junho de 2012:367-394. 
Leitura e escrita femininas no século XIX

Feminine Reading and Writing in the XIX century

\begin{abstract}
This paper aims to analyze women's reading and writing practices in the first half of the $19^{\text {th }}$ century. In this period writing and reading abilities were restricted to a small part of the population, with few indicators of these practices regarding the feminine universe. We analyzed periodicals in circulation during the period, among them O Mentor das Brasileiras (São João del-Rei/MG, 18291832 ), in which there were texts by female writers and references to women's reading practices.
\end{abstract}

Key Words: Gender, Reading Practices, Periodicals, $19^{\text {th }}$ century. 
Este texto busca refletir sobre práticas de leitura e escrita femininas do século XIX. Tais aspectos do cotidiano feminino oitocentista são poucas vezes abordados, obscurecidos pela imagem da mulher reservada ao espaço doméstico, envolvidas portanto, com atividades que prescindiam do domínio dessas habilidades. Tal enfoque é dificultado pela escassez de fontes que possibilitem as investigações e quando muito, permitem apenas fazer inferências em relação a essas práticas.

A escrita privada, a exemplo das correspondências familiares, era uma das poucas formas de participação no mundo da escrita realizadas por mulheres, nas quais não havia restrições no século XIX (Perrot, 2005). No contexto europeu, a autoria feminina, na passagem do século XVIII para o século XIX, quando não era depreciada, se concentrava em gêneros específicos, como as obras de educação (id.ib.:271), os romances e produções nãoficcionais voltadas para crianças (Watts, 2002:165).

Os jornais constituem fontes frutíferas para a discussão desse tema. A produção de impressos periódicos dirigidos e redigidos por mulheres no Brasil começou a surgir a partir da década de 1850 (Buitoni, 1981), sendo o pioneiro, o carioca Jornal das Senhoras, de 1852. A década de 1870 marcou a produção de um grande volume de jornais e revistas com características feministas $e$ esse corpus tem levado à produção de pesquisas que evidenciam a imprensa como forma de expressão e/ou de reivindicação de direitos políticos e sociais, como os trabalhos de Buitoni (1981), Bernardes (1996), Bicalho (1999), Nascimento (2004), Duarte (2003), Andrade (2006) e Araújo (2008). Os demais estudos relacionados à imprensa feminina ou voltada para as mulheres no oitocentos também tendem a concentrar suas análises nas últimas décadas desse século, privilegiando o tratamento da imprensa como produtora de modelos sobre o universo feminino (Buitoni, 1981; Careli, 1997; Oliveira, 2000; Alves, 2003; Nascimento, 2006; Gomes, 2009). A despeito do fato de os jornais voltados para o público feminino produzidos no Brasil estarem presentes desde 
as primeiras décadas do oitocentos ${ }^{1}$, a participação das mulheres na imprensa através da escrita era ainda incipiente nesse período.

Embora de forma "rarefeita", esses e outros jornais voltados para o público em geral trazem textos de autoria feminina $e$ também indicam a existência de práticas de leitura envolvendo o público feminino, o que será desenvolvido ao longo deste texto. Além desses elementos, a análise das leituras sugeridas $e$ "proibidas" para as mulheres também dão pistas sobre o universo mais amplo dessas práticas, que devem ser entendidas em associação com as representações sobre a mulher ilustrada e as leituras consideradas apropriadas para o bello sexo.

\section{Leituras}

Um primeiro ponto a se considerar para a análise das leituras e escritas de mulheres é a parcela da população à qual essas práticas podem ser atribuídas. Sabemos que no Brasil das primeiras décadas do século XIX, o processo de escolarização ${ }^{2}$ da população era ainda incipiente. Assistia-se à produção de aparatos legais visando a organização do ensino, sendo esta, uma das principais intervenções do Estado naquele período (Faria Filho, 2000). Desse modo, tanto as dimensões físicas e materiais quanto a legitimação sociocultural da escola enquanto instância de ensino $e$ aprendizagem se encontravam ainda em sua fase germinal.

Em se tratando de um período em que a escolarização era pensada de forma separada para meninos e meninas, esse segundo público era excluído das escolas públicas até o ano de

\footnotetext{
1 Segundo Buitoni (1981), o primeiro periódico brasileiro voltado para o público feminino, O Espelho Diamantino, foi impresso no Rio de Janeiro no período de 1827 e 1828, sendo seguido de outras iniciativas esporádicas e de curta duração.

2 Faria Filho define escolarização de três formas: 1.políticas voltadas para a produção de uma rede de instituições destinadas ao ensino; 2.a produção de representações em torno da escola como locus de socialização da infância $e$ juventude; 3."processo de submetimento de pessoas, conhecimentos, sensibilidades e valores aos imperativos escolares". Ver em Inácio et alii, 2006.
} 
1814. No ano seguinte, quando sua presença passou a ser registrada nesses estabelecimentos, as meninas constituíam $8 \%$ do total de alunos matriculados e no final do século, em 1889, a proporção chegou a 35\% (Muniz, 2002). Várias eram as razões para a desproporção do público feminino nas escolas, estando entre elas, a resistência das famílias. Fosse por questões de natureza moral ou pela importância das filhas e filhos como força de trabalho para a manutenção familiar, isso indica que a legitimação da escola na sociedade enfrentou percursos tortuosos. Não se pode desconsiderar, no entanto, que o Estado proporcionou oportunidades diferenciadas para meninos e meninas, inicialmente possibilitando a elas um acesso tardio às escolas públicas, em relação aos meninos, além de determinar conteúdos diferenciados, e flexibilizar a obrigatoriedade do público feminino de frequentar a escola (Muniz, 2003; Gouvêa, 2004).

A análise da situação dos estabelecimentos de ensino formais no período pouco auxilia na produção de um cenário razoável para a compreensão das práticas de leitura ou da relação das pessoas com os diversos textos disponíveis para leitura. Os leitores podem ser em número maior em relação aos alunos frequentadores das escolas, visto que o ensino da leitura, escrita $e$ cálculo ainda se dava, em boa medida, pela iniciativa privada (Muniz, 2003; Inácio, 2003; Villela, 2000), pela educação doméstica e, por que não, pelo autodidatismo. Entretanto, saber a quantidade de leitores de um dado período seria apenas uma informação inicial que levaria a várias questões, tais como saber o que as pessoas liam ou, se liam, como liam e o que faziam da leitura - ou o que a leitura lhes provocava.

As dificuldades em se identificar a parcela da população brasileira capaz de ler, no início do século XIX, repousam ainda em outros obstáculos. Inicialmente, trata-se de um período que guarda, ainda, marcas dos séculos anteriores, em que a aprendizagem da leitura antecedia ao da escrita (Hébrard, 1999; Chartier, 1990). Nesse sentido, pode-se supor que aqueles que sabiam escrever, sabiam ler; já nem todos os que liam sabiam 
escrever. Levando-se em conta a análise de inventários feitos em Mariana até o ano de 1822, verifica-se que 63,2\% deles eram assinados $e$ as mulheres assinariam numa proporção de um terço em relação aos homens. Esses dados indicam que para esse grupo, formado pelas camadas proprietárias, a capacidade de assinar o próprio nome era razoavelmente difundida (Villalta, 1997:356), não indicando, no entanto, a capacidade de leitura $e$ nem mesmo a capacidade de escrever, já que a ausência de prática pode fazer com que se perca a habilidade de escrita, que pode se resumir unicamente na assinatura (Chartier, 1990:116). No caso das mulheres, deve-se considerar que a aprendizagem da escrita era proibida nas sociedades antigas, por ser visto como inútil ou perigosa (Chartier, 1990:117). Muitas leitoras jamais aprenderam a escrever ou assinar, tornando mais trabalhosas as pesquisas envolvendo os leitores e leitoras do passado.

Para o período em estudo, sabe-se que era ínfima a parcela de leitores na sociedade $e^{3}$, o que não pode levar à interpretação de que o domínio dessa habilidade era necessário para se ter contato com o conteúdo dos textos. A leitura em voz alta se desenvolvia nos espaços de sociabilidade e no âmbito doméstico, sendo bastante significativo por contemplar o público não leitor. Ao se considerar essa prática de leitura, o elo entre ser alfabetizado e ser leitor se torna frágil e insuficiente para tentarmos nos aproximar da relação entre o público e os jornais no século XIX. Se por um lado as referências à mulher leitora e ouvinte não dão pistas quantitativas ou sobre a abrangência dessa prática, ao menos indicam representações relacionando o universo feminino ao das práticas de leitura, como o trecho a seguir, publicado em $O$ Universal $^{4}$, de Ouro Preto, que possibilita algumas reflexões nesse sentido:

${ }^{3}$ Lilia Schwarcz (1999:118) cita o recenseamento de 1872 segundo o qual 16\% da população brasileira era alfabetizada.

4 Periódico mais longevo, da primeira metade do século XIX, e de tendência liberal, foi impresso em Minas Gerais no período de 1825 a 1842. 
Muito curiosas, muito amigas de saber são as mulheres $e$ por isso não deixam, algumas, de serem discretas. Tendo eu em minha companhia uma Senhora pobre, mas respeitável pelos seus anos e virtudes, que passa todas as horas do dia e da noite a mover os beiços, e as contas de um grosso rosário que traz na mão, quando me chegam as cartas do Rio, e com elas a Gazeta do Brasil, que me envia um amigo; como tenho o costume ou defeito de ler alto, eis que a tal Senhora a passos ligeiros e sempre rezando, se aproxima a ouvir-me, fazendo cruzes, e benzendo-se a cada parágrafo, que ouve ler; ora, notando eu que ela, com a leitura dos outros Periódicos, não só mudava de fisionomia, dando-lhes toda a atenção, mas até fazia parar o giro das contas, e o manejo das cruzes: com a minha costumada pachorra, só para ouví-la, pois que me não era estranho o motivo, lhe perguntei = Senhora o que diz Vm. a estas coisas, que tem ouvido? Por que razão ouve satisfeita, $e$ sem rezar o Diário, o Farol, o Echo, e a Astréa, e se persigna com o semblante pesado, ouvindo a Gazeta? (...) Sr., me disse ela em resposta = quando eu era moça, nunca ouvi tantas sandices, tanta soltura de língua, palavradas tão indecentes, e a caridade para com $\mathrm{o}$ próximo tão escandalosamente insultada (O Universal, $n^{\circ} 40$, $15 / 10 / 1828: 3)$

Esta cena, seja ela parcial ou totalmente criada, representa um fragmento factível do cotidiano oitocentista. A intenção inicial, de mostrar que uma senhora pobre e iletrada tem bom senso para estabelecer afinidade política com os periódicos liberais e rejeitar um periódico restaurador, mostra também a interpenetração dos universos dos leitores e não-leitores no ambiente doméstico, o que resulta na formulação de uma opinião - ou ao menos se espera que isso ocorra. Em um outro trecho, dessa vez do periódico $O$ Mentor das Brasileiras, impresso em São João del-Rei - MG entre 1829 e 1832, um correspondente comenta que "certa senhora desta vila da Campanha, ouvindo ler $o n^{\circ}$ da Aurora 
Fluminense..." (O Mentor das Brasileiras, 22/10/1830:370), o que indica que a interação entre leitores e ouvintes ocorre, mas segue sendo importante estabelecer a distinção entre quem lê e quem escuta a leitura, visto que foi destacada a forma como a senhora campanhense teve acesso à informação do periódico.

Em Minas Gerais do início do século XIX, podem ser encontrados indícios da institucionalização da leitura em voz alta associada à sociabilidade, e a leitura para os leitores neófitos ou não leitores. Como exemplo, temos o estatuto da Sociedade Philopolytechnica de São João del-Rei, um estabelecimento projetado para ampliar as práticas de leitura na vila (Morais, 2002:94), que previa a assinatura de periódicos nacionais $e$ estrangeiros e que, no gabinete de estudos, "os Periódicos em línguas menos vulgares poderão ser lidos a muitos por um intérprete, que queira a isso prestar-se" ${ }^{5}$

Os jornais apresentam, ainda, muitas referências às mulheres leitoras. O Mentor das Brasileiras, um semanário dedicado às "estudiosas brasileiras", cujo redator era José Alcibíades Carneiro, professor de gramática latina, ao iniciar o segundo trimestre de publicação, dizia:

Chegamos com felizes auspícios ao n. 14 de nossa folha, a qual consta-nos ter obtido bom acolhimento pelas nossas Patrícias não só de Minas como também da Corte, as quais em grande número têm assinado a presente folha $(O$ Mentor das Brasileiras, 05/03/1830:105).

Um outro periódico voltado para as mulheres também começava a circular, não sendo esse o seu público exclusivo, de

\footnotetext{
5 Projectos d'Estatutos para a Organização da Sociedade Phylopolytechnica emprehendida em a Villa de São João D'El Rei (Revista do Archivo Publico Mineiro, 1899:829). Importante salientar que a Sociedade Philopolitechnica não chegou a se estabelecer. De acordo com parecer do Visconde de Cayrú, um dos motivos seria a localização remota da corte e, portanto, estar longe dos "olhos do governo" (id.ib.:839)
} 
acordo com uma correspondência publicada, em que um jovem escreve a seu pai: "Remeto esse Periodicozinho intitulado = Manual das Brasileiras = dedicado às mulheres, para minha Mãe e Manas: é uma folha bem boa, e meu Pai há de gostar muito dela". ${ }^{6}$ Não podemos esquecer que esses comentários estão sendo veiculados pelos próprios jornais, que certamente, buscavam favorecer sua auto-imagem. Produz-se, através desse discurso, a imagem da mulher como leitora ávida dos periódicos liberais, interessada e atuante nos negócios públicos. Segundo o Tribuno do Povo, elas "são por natureza amantes da liberdade e nós vemos que a maior parte das Senhoras Brasileiras se dedicam à leitura dos Periódicos Liberais, e tomam parte nos negócios de seus Concidadãos". ${ }^{7}$ Em uma correspondência privada, publicada em $O$ Mentor, a redatora dizia:

Tenho notado que a maior parte das senhoras, principalmente aquelas em quem transluz alguma instrução, não se tornam indiferentes aos negócios públicos: elas se dão à leitura dos Periódicos com muita avidez, e disputam com juízo com alguns publicistas (O Mentor das Brasileiras, 04/06/1830:214).

A referência a "periodicozinho" quando se trata daqueles voltados para mulheres está relacionado ao seu tamanho reduzido, se comparado a outros do mesmo período. Apesar de as medidas dos diversos jornais do início do século XIX variarem, indicando não haver uma padronização entre eles, se comparadas às de $O$ Mentor das Brasileiras, que eram de 14,7 x 19,7 centímetros, este era visivelmente menor que os demais. $\mathrm{O}$ Universal, de Ouro Preto, media $30 \times 21 \mathrm{~cm}$; o Farol Paulistano, 35 x $25 \mathrm{~cm}$ e em 1831 reduziu suas dimensões para $32 \times 23 \mathrm{~cm}$; o carioca Astréa media 31 × $21 \mathrm{~cm}$; O Espelho Diamantino, também

\footnotetext{
${ }^{6}$ Astro de Minas (16/03/1830:4) se referindo ao periódico impresso em São Paulo.

7 O Mentor das Brasileiras (18/02/1831:502) citando trecho retirado do Tribuno do Povo, periódico do Rio de Janeiro.
} 
do Rio de Janeiro, media $22 \times 15 \mathrm{~cm}$, e era o único que se aproximava das medidas de $\mathrm{O}$ Mentor. O periódico paulistano Manual das Brasileiras provavelmente também tinha tamanho reduzido, visto ser referido como "periodicozinho" ou "pequena folha". Note-se que o tamanho dos periódicos voltados para as senhoras equivalia aproximadamente à medida dos demais periódicos dobrados ao meio.

Uma possível explicação para o tamanho reduzido desses periódicos é o fato de os livros voltados para o público feminino e para a educação de jovens serem impressos em tamanho in octavo, ou seja, como livretos de bolso. Às mulheres seria produzida uma bibliografia em formato reduzido e elas estariam familiarizadas à leitura de obras com essas características; possivelmente a produção dos jornais voltados para as mulheres tinha, como referência, essa materialidade já característica dos livros voltados para esse público.

\section{Escritas}

As referências à escrita feminina são indicadas, em primeiro momento, nos prospectos dos periódicos voltados para mulheres, sendo um deles, $O$ Espelho Diamantino, do Rio de Janeiro, que afirmava:

Inútil é declarar que receberemos com o maior gosto $e$ inseriremos em nosso periódico, as obras de Poesia e Prosa que nos serão transmitidas, convidando com especialidade as Senhoras para que nos honrem com os seus ensaios $e$ produções, seguras do nosso discreto silêncio, se um excesso de modéstia as obriga a desejar que seu nome fique subtraído aos elogios da fama (O Espelho Diamantino. Prospecto sem data:4).

Da mesma forma, O Mentor das Brasileiras, em seu prospecto (30/11/1829:3), convidava as senhoras para que "nos dirijam os seus ensaios de literatura, que contenham matéria 
importante por sua natureza, ficando certas de nosso inviolável segredo quando assim o exijam" (O Mentor das Brasileiras, prospecto).

Esses trechos sugerem um retrato da sociedade feminina da época: de não serem raras as senhoras que produziam ensaios e poesias, o que de certa forma era de conhecimento "público", mas que a discrição e o anonimato eram desejados ou necessários.

Em O Mentor das Brasileiras, cujo conteúdo veiculado possibilita classificá-lo como noticioso e de variedades, escritas atribuídas à autoria feminina totalizam 56 das 1.024 páginas, o que representa $5,4 \%$ do volume total do conteúdo impresso. ${ }^{8}$ Nessas páginas se encontram principalmente hinos, sonetos e poesias (21), correspondências de leitoras (31) e transcrições de discursos de professoras de escolas públicas de meninas (12) quando da realização dos exames públicos semestrais. Os escritos poéticos, quando declarada a autoria, são em boa parte de Beatriz Francisca de Assis Brandão, professora da escola pública de primeiras letras de meninas de Ouro Preto. As temáticas tratadas são quase que exclusivamente a independência do Brasil e o enaltecimento da constituição, como o poema a seguir que possui 19 estrofes.

Ergue o colo, ó Pátria amada,

Teu triunfo livre canta

De servil férrea cadeia

Os braços livres levanta.

Tristes mães, filhos, esposas,

Por tão desastrosa sorte

Entregues a vil penúria

A infâmia pior que a morte

\footnotetext{
${ }^{8}$ As demais seções que compunham o jornal são: anedotas, correspondências, educação, fábula, notícias do interior, nacionais e estrangeiras, modas, história do Brasil e política. Não possuía ilustrações, à semelhança dos periódicos das primeiras décadas do século XIX. Para um maior aprofundamento sobre esse jornal, ver Jinzenji, 2010.
} 
Varões, que o rigor vencestes
Da lei iníqua e pesada
Vede ainda em vossos dias
Nossa Pátria libertada
Esses que os ossos deram
À ardente Africana área
Entoaram nos Elíseos
Vivas à Augusta Assembléia.
(O Mentor das Brasileiras, 05/03/1830:111 e 112)

Beatriz Francisca de Assis Brandão demonstrava familiaridade com o universo da escrita e da imprensa e, em outros jornais, como $O$ Universal, de Ouro Preto e O Farol Paulistano, de São Paulo, são encontrados textos $e$ correspondências de sua autoria. Beatriz Brandão viria a se tornar conhecida como escritora e poetisa a partir da segunda metade do século XIX (Vasconcellos, 2000).

Em O Mentor das Brasileiras, os discursos atribuídos a professoras de escolas públicas seguiam à publicação dos resultados dos exames, feita geralmente alguns dias após a realização do ato público. Os discursos teriam sido proferidos quando das aberturas dos exames públicos, como o que segue, atribuído à professora Policena Tertuliana de Oliveira, professora da escola de São João del-Rei.

O Dever que nos impõe a Lei, minhas queridas Alunas, de vir duas vezes no ano a este lugar dar contas ao respeitável Público de nossos trabalhos parece sem dúvida ter servido de um grande estímulo para procurarmos desempenhar com mais assiduidade nossas obrigações. Feliz portanto um tal preceito, quando dele se tira tão belos resultados de nosso aproveitamento! As vantagens que temos obtido destas nossas periódicas reuniões, são bem patentes e não necessitam de mais provas; o Público, que nos observa com tantas demonstrações de interesse, está bastantemente inteirado se não de meu zelo em cumprir tão importantes 
deveres a que estou ligada, ao menos da vossa atividade, do vosso amor pelos estudos e do natural desenvolvimento do vosso espírito. Eis o que me anima hoje a reiterar com o mesmo gosto os exames das lições que vos hei dado; $e$ suposto que por esta vez eu não possa apresentar muitas de vós com o adiantamento que porventura apresentei nos exames passados, contudo espero que não sereis reputadas por omissas, atendendo o tempo e o atraso, em que vos acháveis, quando principiastes receber minhas lições; talvez que pelos futuros exames eu possa apresentar algumas de vós completamente aprovadas; entretanto nós faremos criadoras da indulgência do respeitável Público, se fizermos aparecer os nossos trabalhos, livres do temor, que quando se apodera do nosso espírito, costuma tolher o desenvolvimento de nossas idéias. Vós sabeis (e o mesmo Público é testemunha) que eu vos tenho educado não só pelos preceitos adotados nas mais escolas mas também segundo o espírito do nosso século pelo Sistema Constitucional, de que vos tenho dado profícuas lições no nosso sagrado Código, o que talvez para o futuro servirá de grande utilidade à Pátria, porque muito convém que as doutrinas liberais se propaguem por todas as classes indistintamente e ainda direi que com preferência no nosso sexo, visto que os homens recebem dele a sua primeira educação, e com o leite podem beber boas ou más doutrinas à proporção do estado de civilização ou embrutecimento em que se achar o sexo feminino; porém, graças sejam dadas ao atual Sistema, porque ora nos governamos por ele é que temos entrado na partilha de uma mais nobre civilização, de que estávamos privados. Não será pois alheio de nosso dever se dermos mostras de gratidão, exclamando com vivo entusiasmo, Viva a nossa Santa Religião $=$ Viva a Constituição $=$ Viva SS. MM. II. = Viva a Assembléia Geral Legislativa = e Viva o Povo Brasileiro (O Mentor das Brasileiras, 17/12/1830:434-435).

O anonimato era predominante, não só por parte das mulheres como também pelos homens. Destaca-se, no entanto, o 
fato de as professoras não utilizarem esse recurso, como acontece nos discursos atribuídos a elas, apesar da fidedignidade dessas autorias ser questionável. Além de Beatriz Brandão e Policena Tertuliana de Oliveira, outras professoras que ganharam destaque no jornal foram Jacinta Carlota de Meireles, da escola de Baependi, Luiza Tarmer, da escola de São Gonçalo, Angélica Lucinda da Conceição, da província de Piauí. Algumas poucas senhoras também assinavam correspondências, como é o caso de Maria Magdalena de S. Anna, de Tamanduá, Luiza Roza de Souza, de Sabará e Maria Guilhermina da Rocha.

Grande parte das correspondências enviadas para O Mentor das Brasileiras constituía opiniões de supostas leitoras. A dificuldade na verificação da fidedignidade dessas cartas se dá pelo uso de pseudônimos, que correspondem a uma lista inspirada em temas político e morais, tais como A Brasileira Constitucional, Huma sua Patrícia, A Patriota Baependyana, Brasileira inimiga do despotismo, Amiga do bom gosto, A Crenda da Minerva, Varinha de marmelo. Entretanto, mesmo se considerando que sejam correspondências forjadas por homens ou pelo redator, indica aquilo que, a partir dos referenciais masculinos, definiria a brasileira ilustrada, virtuosa e patriota.

Ao contrário do que se possa esperar, nesse jornal não eram publicadas somente as correspondências elogiosas, mas também as críticas feitas por leitoras, geralmente insatisfeitas, que solicitavam mudanças ou demandavam assuntos. Considerandose essas correspondências verídicas, elas indicariam a recepção do periódico. $\mathrm{Na}$ contrapartida negativa, podemos considerar que essas correspondências foram forjadas pelo redator visando justificar uma mudança de rumo ou tendência que se pretendia operar.

Um desses exemplos pode ser verificado a partir da correspondência enviada por alguém que assina Huma que não se esquece ao Mentor das Brasileiras. Ela se queixava do súbito desaparecimento da seção Parte Histórica, que constituía uma narrativa sobre a história do Brasil, desde seu descobrimento. Esse 
conteúdo costumava ocupar de uma página a página e meia de quase todos os números até então, e a publicação fragmentada, interrompida a cada número, levava a uma leitura também fragmentada e sucessivamente interrompida.

Como sei que quando se promete alguma coisa (ao Público principalmente) está o prometente obrigado a satisfazê-la, cuido que não levará a mal que lhe faça uma pergunta. Porque se não tem continuado a História do Brasil, havendo desempenhado tão dignamente até aqui a parte política que lhe corresponde? Não sei a que atribua uma tão criminosa falta (...)

(O Mentor das Brasileiras, 30/06/1830:245.)

Logo em seguida a essa correspondência, o redator se desculpa, justificando a retirada desse assunto, que teria sido substituído por outros, a partir da sugestão de alguns amigos. Desde então, a seção, que estava ausente do jornal, voltou a estar presente em cada número até o fim da circulação de $O$ Mentor, em 1832. A flexibilidade apresentada pelo redator sugere, em princípio, a preocupação em responder às expectativas de leitoras como estratégia de sobrevivência do próprio jornal, visto que a "fidelidade" dos leitores era imprescindível para a manutenção de sua produção. Mas isso indica também que o leitor possuía um lugar privilegiado na produção de jornais no período, sendo inerente a esse processo, a sua participação; o feedback do leitor indicaria, em alguma medida, o nível de aceitação do periódico.

As mudanças de direção nas opiniões veiculadas pelo jornal, estabelecidas solitariamente ou de acordo com as respostas de leitoras, nem sempre seguiam a linha estabelecida no prospecto, sendo um dos exemplos mais claros, a discussão referente à moda. Anunciado como tema importante para as mulheres, as matérias referentes à moda estiveram presentes nos primeiros números e foram abolidas posteriormente. Algumas leitoras, insatisfeitas, solicitavam a presença desse assunto, como aquela que assina $A$ Sentinella do Mentor. 


\begin{abstract}
Srs. Redactores do Mentor
Bem certa estou, que v.m. prometeu no seu prospecto darnos alguns artigos sobre modas, a cujo prometido satisfez em parte no N. 6, porém até agora não tem aparecido mais artigo algum a semelhante respeito, o que se tem feito assaz notável mormente por estarmos em tempos de festividades, em que é usual a variedade no traje (...)

(O Mentor das Brasileiras, 10/04/1830:148-149)
\end{abstract}

Ao que os redatores respondem logo em seguida, no mesmo número:

Reflexões

Muito agradecemos à nossa Correspondente a advertência, que nos faz pela falta que temos tido em não apresentarmos mais artigos sobre modas; porém é desculpável o nosso silêncio a semelhante respeito, por quanto não nos permite ter sempre notícias frescas da Corte sobre as modas, que por lá estão na melhor aprovação de bom gosto, e mesmo quando nos fosse fácil obtê-las, nós não seríamos pródigos em espalhá-las; por isso mesmo, que não desejamos na nossa pátria a superfluidade do luxo, causa principal da ruína total de muitas famílias, que constituindo todo o seu patriotismo no vestuário cavam a ruína dos filhos, as vezes com a mesma perca dos bons costumes. O nosso alvo principal é a ilustração do espírito das Jovens filhas do Brasil, e por isso cuidaremos menos em modas, que em sãs doutrinas. Além disto, nos parece uma espécie de pouco senso o querer-se sempre imitar no traje aos Estrangeiros, como se eles sejam os proprietários do bom gosto; por ventura as nossas patrícias não são igualmente dotadas de bastante vivacidade de espírito para por si mesmas excogitarem o melhor gosto de trajar? De certo que sim; pois então cuidemos, sendo precisos, nós mesmos na invenção das modas; e não vamos ser unicamente imitadores das Nações estrangeiras. 
Percebe-se que, mesmo antes dessa resposta, O Mentor estaria caminhando para uma tendência ao repúdio às modas $e$ ao luxo, apoiada por outros periódicos e outras leitoras, numa crítica insistente à importação de padrões franceses em prol da valorização de estilos e produtos nacionais. Esse movimento contraria a tendência dos periódicos voltados para as mulheres que, mesmo nas fases posteriores, seguirão tratando o tema "moda" com destaque (Buitoni, 1981). Tal "incongruência" será motivo de tensão entre o redator e as leitoras-correspondentes que insistentemente encaminharão suas insatisfações ao jornal. Uma delas, que assina Amiga do bom gosto, escreve uma extensa correspondência, que segue.

Srs. Redactores do Mentor.

Suposto me tenham satisfeito as suas reflexões sobre o luxo, $e$ as modas, com as quais tanto se importam as pessoas do meu sexo, contudo eu ainda não me posso inteiramente acomodar com suas ideias por vezes expendidas; pois se eu pretendesse fazer a apologia do luxo e das modas poderia autorizar-me com o exemplo de quase todos os povos do Mundo, desde os antigos Patriarcas até o nosso tempo. Entre os presentes que Abimelech fez a Abrahão destinou quarenta peças de prata para que comprasse um véu a Sara, e se um véu custava então quarenta peças de prata, que equivalem a 50 moedas, devemos supor que o luxo daqueles tempos não cedia ao das nações modernas. (...) Verdade é que o Luxo e as Modas foram sempre o alvo de crítica dos filósofos; mas estes ataques não puderam prevalecer ainda contra a força irrepetível do costume; porque o costume é a principal base da opinião pública, desta Soberana caprichosa, que estende o seu império por toda a terra.

É certo que o Luxo e as Modas têm os seus inconvenientes; mas também produzem grandes vantagens, promovendo os progressos das Artes, e fomentando diferentes ramos da indústria, que fazem subsistir muitos milhares de indivíduos, 
que a impossibilidade de se entregarem à cultura da terra reduziria à ultima miséria.

Portanto, Srs. Redatores, sem que eu seja taxada de nimiamente [sic] cobiçosa das modas e muito menos de [ilegível] em falar em objetos tão delicados, de que melhor as deviam encarregar os grandes economistas, jamais aprovarei o total abandono do luxo e das Modas prudentes, que nos dando certo realce que nos deve ser próprio, não são todavia incompatíveis com a verdadeira virtude; pois que bem certa estou, em que a mediocridade é que constitui a virtude a que todos os extremos são sempre viciosos.

Perdoe-me Srs. Redactores, se eu nestas reflexões tenho ultrapassado os limites da civilidade; pois que não acostumada a [ilegível] por escritas minhas idéias talvez escapasse sem reflexão algum [ilegível] pouco culta; mas no entanto, tirando qualquer acrimônia que possa ter, queira publicar pela sua estimável folha, no que muito obriga a huma que se assigna a Amiga do bom gosto

(O Mentor das Brasileiras, 05/05/1830:182-183)

Apesar do protesto manifestado pela carta da leitora, o assunto moda, que tinha tido uma inserção tímida até então, não voltou a ser publicado, salvo nos números 26 , que discute sobre a moda em Paris, e 34, em que se discute sobre penteados. O que parece ter sido uma tentativa de dissuadir as mulheres a se interessarem por esse assunto, sofreu idas e vindas, sugerindo dificuldade em tomar um posicionamento definitivo. Uma solução que parecia ser viável foi a de deslocar o foco para assuntos políticos, como sugere a citação abaixo, supostamente uma correspondência entre amigas que foi cedida por uma delas para publicação.

Vós me importunais para que eu vos dê notícias sobre as modas, que mais se usam nesta corte; mas eu sou sincera, $e$ por isso atrevo a estranhar-vos esse vosso demasiado desejo de um objeto, que (apesar da natural propensão do 
meu sexo) eu o reputo digno de mui pouca atenção; quisera antes, que me importunásseis pelas notícias do Estado, que parecendo longe do nosso alcance, não consideram contudo dignas do desprezo das pessoas do nosso sexo (...) $F$

(O Mentor das Brasileiras, 04/06/1830:211-212)

$\mathrm{O}$ assunto das modas gerou ainda uma correspondência cujo conteúdo permite pensar em outro tipo de expectativa em relação ao jornal; a de que ele pudesse substituir as cartas particulares. Uma leitora, que assina com o pseudônimo de Sentinella do Mentor, se queixa da ausência de notícias sobre moda, previstas no prospecto, e comenta sobre a insatisfação de uma amiga em semelhante assunto:

Eu tinha uma amiga no Rio de Janeiro que continuamente me comunicava as modas existentes; com a aparição do Mentor mandei-lhe dizer que lhe poupava aquele trabalho; porém fiquei enganada, e no entanto nem de cá nem de lá tenho notícia das modas da Corte.

(O Mentor das Brasileiras, 10/04/1830:148-149)

Por fim, o que pode ser concluído é que redatores e leitoras buscavam um consenso que nem sempre poderia atender às diferentes demandas. A postura final adotada pelo redator se harmoniza com o conjunto das matérias que compõe o jornal, em consonância com o posicionamento liberal moderado, em que a "moderação" era a tônica: a moderação no vestir e se adornar estava diretamente ligada à crítica ao luxo característico das monarquias absolutistas e ao estrangeirismo; essa moderação deveria se desdobrar no controle dos afetos, mesmo em relação ao cônjuge, que deveria ser tratado como amigo. $\mathrm{O}$ casamento deveria ser resultante da afinidade e respeito mútuo e não sustentado pela beleza física, como será discutido adiante. 


\section{Sugestões de leitura e leituras contra-indicadas}

As aventuras de Telêmaco, de Fénelon, foi indicada pela professora Beatriz Francisca de Assis Brandão em uma breve matéria publicada em $O$ Mentor, sob o título $O$ bello sexo. Nessa matéria, a professora reflete sobre a curta duração da beleza física e critica as mulheres que, escravas da vaidade, procuram se fazer admiradas unicamente pelos encantos da juventude. Em contrapartida, defendia o cultivo do espírito, a instrução e a aquisição do gosto pela leitura. Em suas palavras,

...aquela que sacrificou algumas horas da sua Toilette a um estudo sólido, e ocupações razoáveis, que pensa, combina, e trata polidamente as pessoas, não será, em certo tempo, objeto de suspiros; mas obterá a estimação e conceito das gentes sensatas, e terá prazeres para todos os períodos da sua idade. Portanto, amadas patrícias, trabalhai para que as vossas filhas saibam conhecer o verdadeiro mérito: dai-lhes bons livros: fazei-as ler e até decorar aquele capítulo em que Fenelon faz falar Telêmaco sobre as qualidades de Antíope e, se todas beberem esta sábia lição, será realmente bello o nosso sexo (O Mentor das Brasileiras, 12/03/1830:118).

No trecho a que a professora Beatriz se refere, Telêmaco descreve as qualidades de Antíope como as de uma futura esposa perfeita: "o que me atrai nela é seu silêncio, sua modéstia, seu recolhimento, seu trabalho assíduo, sua indústria pelos trabalhos de lã e bordado, sua aplicação em conduzir toda a casa de seu pai, desde a morte de sua mãe". 9

Outros livros indicados reincidem na tendência de postular sobre a educação moral necessária para a formação da mulher virtuosa, buscando reforçar valores ligados à vida familiar $e$ conjugal. Entre eles, encontra-se um certo Tratado de educação pública e privada, de M. de Suzanne, do qual, segundo O Mentor,

${ }^{9}$ Fénélon (1920:489) [tradução minha]. 
"bastará que se leia a eloquente introdução, com que esse autor principia o seu Apêndice relativo à educação das meninas." $(O$ Mentor das Brasileiras, 14/05/1830:188). ${ }^{10}$ Aparentemente, esse apêndice é transcrito em seguida, no qual são descritas as funções de homens e mulheres na sociedade. Assim,

Se na ordem social, a mulher não representa papel algum aparente, se a administração das transações particulares, os empregos e funções públicas, a segurança e direitos dos Cidadãos, enfim, se a defesa e os mais elevados interesses da pátria são confiados à sagacidade, luzes e coragem do homem, ela não deixa de ter muitas vezes grande influência sobre os negócios, exercício do poder, ações brilhantes e mesmo sobre os grandes acontecimentos que mudam a fortuna dos estados. Mas isto não é mais do que um papel de [ilegível] que não entra nos deveres das mulheres. As suas [ilegível] reduzem-se especialmente a vigiar na educação de seus filhos, no governo doméstico, a ajudar seu marido com sãos conselhos, a consolá-lo nos desgostos, a tratá-lo nas enfermidades, a tirá-lo do caminho do erro por meio da doçura, paciência, persuasão e amizade, em duas palavras, a concorrer para o bem da família por sua terna solicitude, bom senso, razão, paciência, coragem, enfim, por uma conduta judiciosa e adesão sem limites (id.ib.:189).

Em uma matéria extraída do periódico pernambucano $O$ Popular, "Educação - As Moças", advertências são feitas em relação às leituras das jovens: "Tornamos a lembrar aos pais a boa lição de suas filhas: se estas hão de empregar o tempo em leituras de novelas, pela maior parte despertadoras de paixões criminosas, leiam as sapientíssimas Epístolas de S. Paulo; leiam a imitação de Christo de Kemps, leiam para instrução e recreio, o Telêmaco do virtuoso Bispo Fénelon, e a Escola dos costumes pelo Abade

${ }^{10}$ Extraído de Aurora Fluminense, n. 327. 
Blanchard" (O Mentor das Brasileiras, 03/12/1830:410-420). ${ }^{11}$ Ao final desta lista, o redator de $O$ Popular faz o seguinte comentário, omitido por $O$ Mentor: "Deus nos livre de moças metidas a filósofas e discursistas".

O periódico $O$ Popular, que em seu um ano de existência se destacava pelas matérias relacionadas à educação das mulheres, relacionava a doutrina cristã como a principal leitura a ser feita pelas mulheres. Apontava o perigo da leitura de novelas, pelo caráter inverossímil, elementos amatórios e paixões exageradas presentes nesses tipos de leitura. Entretanto, nas palavras do redator,

não reprovamos absolutamente o honesto recreio das novelas; mas é preciso que os pais examinem a qualidade das novelas; os contos morais de Marmontel podem ser lidos pela mocidade sem perigo, e com vantagem pelas excelentes máximas que encerram; mas a principal leitura dos meninos deverá ser o Evangelho e as Epístolas de S. Paulo (O Popular, 07/08/1830:79-80).

A religião aparece como argumento para se considerar o Emílio de Rousseau (refere-se a "Emília") como obra "desonrada" $e$, entre outros motivos, é citada como obra contra-indicada:

Abramos a Emília do eloquente Rousseau, veremos como este homem extraordinário tem reunido em seu livro, debaixo do ponto de vista o mais sedutor possível, aquilo que se acha de mais racional em todos os Instituidores conhecidos. Este livro é cheio de maravilhosos métodos, $e$ sublimes lições. Mas que desgraça! A maior parte de seus métodos, tão belos em teoria, são impraticáveis no exercício. Suas sublimes lições de moral são bem extravagantes, por se propor a exterminar a sociedade, separando os homens, que se devem unir. O seu livro enfim é quase todo desonrado pelas suas animosidades contra a

${ }^{11}$ Extraído do Popular, no 38 (09/10/1830:151). 
Religião! Ah! Este livro, que devia e podia ser o Código da sabedoria, o tipo dos costumes, e a fonte da felicidade pública não é mais do que um resumo de escândalos, onde algumas verdades úteis são sufocadas por erros, que as envolvem de todas as partes.(...) é preciso escolher com prudência o que há de bom e judicioso nos autores, cujas lições vamos beber, fazer disto um plano de educação civil e Religiosa, e então começaremos a gozar da esperança de um dia vermos jovens bem moralizados, homens honestos e Cidadãos proveitosos $(O$ Mentor das Brasileiras, 04/03/1831:530).

As críticas perceptíveis se referem à artificialidade dos métodos da "educação natural" de Emílio, pela hipotética e irreal situação de isolamento de preceptor e educando do convívio social; outrossim, seu posicionamento crítico à religião teria desagradado os leitores e leitoras em adotar a obra como "código de sabedoria". Essas parecem ser as únicas restrições à obra de Rousseau que, no entanto, segue sendo referência para O Mentor e demais periódicos com os quais dialoga, para desenvolver diversos temas relacionados à educação da mulher, à amamentação, à obediência ao homem, etc.

Uma suposta - e interessante - correspondência da leitora que assina Varinha de marmelo denunciava o anúncio de venda de um livro, considerado pecaminoso, intitulado Significação amorosa das Flores, ou Linguagem dos Amantes, dedicada à mocidade, publicado no periódico restaurador Amigo da Verdade, de São João del-Rei. O livro estaria à venda na tipografia de mesmo nome. Segundo a correspondente,

dar-se à luz uma obra, que ninguém ainda se lembrou de a imprimir, e que apenas corria manuscrita por mãos de gente a mais imoral, só estava reservado para a Tipografia do Amigo da Verdade em São João del-Rei! (O Mentor das Brasileiras, 21/07/1830:269). 
Trata-se de um relato interessante, pois se refere à "imoralidade" em circulação por meios alheios ao impresso; fica a pergunta sobre quão intenso era o "submundo" da circulação manuscrita $e$, consequentemente, a real batalha que estava sendo travada pelos jornais em busca da moralização de leitoras e leitores.

Por fim, para complementar a formação moral e cívica das mulheres, o texto com o maior índice de recomendação era a Constituição do Império, considerada doutrina máxima e leitura obrigatória de todo cidadão, além de ser indicada como texto para a aprendizagem da leitura a ser utilizado nas escolas primárias. Sua presença se fazia marcante nas escolas, nas epígrafes de diversos periódicos (Jinzenji, 2006) e a venda era difundida em larga escala, sendo anunciada por 320 réis nas tipografias. $\mathrm{O}$ redator de $\mathrm{O}$ Mentor das Brasileiras assim dizia, em referência à primeira lei imperial relativa à organização da instrução pública:

hoje, porém, que a Nação principia com a saudável Lei de 15 de Outubro de 1827 a cuidar melhor na vossa educação moral (...); aplicai-vos decididamente aos primeiros estudos, que a Nação vos promoverá os segundos; tende sempre diante de vossos olhos o sagrado código da nossa Constituição para quando a sorte vos fizer mães de famílias, imbuir a vossos filhos nestas santas doutrinas, únicas que podem fazer uma política perfeita na nossa pátria.

(O Mentor das Brasileiras, 05/03/1830:106.)

\section{Reflexões finais}

Este trabalho buscou contribuir com reflexões acerca das práticas de leitura e escrita de mulheres privilegiando como fonte a imprensa periódica da primeira metade do século XIX. Como se pode perceber, a participação na imprensa através da escrita, como mais uma possibilidade de expressão das mulheres, era ainda incipiente nas primeiras décadas do século XIX brasileiro. É a partir da segunda metade do século XIX que jornais redigidos e dirigidos por mulheres começam a surgir no Brasil, dando origem 
à chamada Imprensa feminina. Já a leitura, ou as práticas de leitura pelo público feminino são menos acessíveis; os leitores $e$ leitoras nem sempre deixam pistas das suas práticas (Darnton, 1992), o que não impede de se buscar, através de fontes indiretas, uma aproximação dessa dimensão do mundo social feminino.

\section{Referências bibliográficas}

ALVES, Gislene. Nas sendas do progresso: cidade, educação e mulheres (Pindamonhangaba - 1860-1888). Dissertação de Mestrado, História, PUC-SP, 2003.

ANDRADE, Fernanda A. de A. Estratégias e escritos: Francisca Diniz e o movimento feminista no século XIX, 1873-1890. Dissertação de mestrado, História, UFMG, 2006.

ARAÚJO, Maria da Conceição P. Tramas femininas na imprensa do século XIX: tessituras de Inês Sabino e Délia. Tese de doutorado, Teoria Literária, PUC-RS, 2008.

BERNARDES, Elizabeth L. Mulheres cuiabanas na primeira república. Dissertação de mestrado, Educação, UFMT, 1996.

BICALHO, Maria Fernanda Baptista. A imprensa feminina e a campanha sufragista no início da República. Caderno Feminino. Uberlândia, vol.6, n6, jan/jul 1999, pp.7-19.

BuITONI, Dulcília H. S. Mulher de papel. A representação da mulher pela imprensa feminina brasileira. São Paulo, Edições Loyola, 1981.

CARELI, Sandra da S. Texto e Contexto: virtude e comportamento sexual adequados às mulheres na visão da imprensa porto-alegrense da segunda metade do século XIX. Dissertação de Mestrado, História, UFRGS, 1997.

ChARTIER, Roger. As práticas da escrita. In: ARIÈs, P.; DuBY, G. (orgs.) História da vida privada. Da Renascença ao Século das Luzes, vol. 3. São Paulo, Companhia das Letras, 1990, pp.113-161.

DARNTON, Robert. História da Leitura. In: BURKE, Peter. A escrita da história. Novas Perspectivas. São Paulo, Editora UNESP, 1992, pp.199-236. 
Leitura e escrita femininas no século XIX

DE LUCA, Leonora. "Amazonas do Pensamento": a gênese de uma intelectualidade feminina no Brasil. Tese de Doutorado, Ciências Sociais, Unicamp, 2004.

DUARTE, Constância L. Feminismo e literatura no Brasil. Estudos Avançados vol. 17 no 49, São Paulo, USP, set/dez 2003, pp.151-172.

. Nísia Floresta: vida e obra. Natal, UFRN, 1995.

FARIA FILHO, Luciano M. de. Instrução elementar no século XIX. In: LOPES, Eliane Marte T. S.; FARIA FILHO, Luciano M. De; VeIGA, Cynthia G. (orgs.) 500 anos de Educação no Brasil. Belo Horizonte, Autêntica, 2000, pp.135-150.

GOMES, Gisele A. Entre o público e o privado: a construção do feminino no Brasil do oitocentos, 1827-1846. Dissertação de mestrado, História, UFJF, 2009.

GouvÊA, Maria Cristina S. de. Meninas nas salas de aula: dilemas da escolarização feminina no século XIX. In: FARIA FILHO, Luciano M. de (org.) A infância e sua educação. Materiais, práticas e representações. Belo Horizonte, Autêntica, 2004, pp.189-212.

HÉBRARD, Jean. Três figuras de jovens leitores: alfabetização e escolarização do ponto de vista da história cultural. In: ABREU, Márcia (org.). Leitura, história e história da leitura. Campinas, FAPESP, ABL, Mercado de Letras, 1999, pp.33-78.

INÁCIO, Marcilaine $\mathrm{S}$. O processo de escolarização e o ensino de primeiras letras em Minas Gerais (1825-1852). Dissertação de mestrado, Educação, UFMG, 2003.

; FARIA FILHO, Luciano M. de; ROSA, Walquíria M.; SALES, Zeli E. S. de. Escola, Política e Cultura: a instrução elementar nos anos iniciais do império brasileiro. Belo Horizonte, Argumentvm, 2006.

JINZENJI, Mônica Y. Cultura impressa e educação da mulher no século XIX. Belo Horizonte, Editora da UFMG, 2010.

. O protagonismo dos jornais na ampliação das práticas de leitura em Minas Gerais nas primeiras décadas do século XIX. VI Congresso Luso-brasileiro de história da Educação. Uberlândia - MG. 
Mônica Yumi Jinzenji

Anais eletrônicos. 2006.2 Disponível em: $<$ http://www.faced.ufu.br/colubhe06/anais/arquivos/eixo5.htm $>$

MoRAIS, Christianni C. "Para aumento da instrução da mocidade da nossa pátria": estratégias de difusão do letramento na Vila de São João del-Rei (1824-1831). Dissertação de mestrado, Educação, UFMG, 2002.

Muniz, Diva do C.G. Um toque de gênero: história e educação em Minas Gerais (1835-1892). Brasília, Editora Universidade de Brasília/ FINATEC, 2003.

- Construindo diferenças: a escolarização de meninos e meninas nas Minas oitocentistas (1834-1889). In: LOPES, Ana Amélia Borges M.; GonÇALVES, Irlen Antônio et alii. (orgs.) História da Educação em Minas Gerais. Belo Horizonte, FCH/FUMEC, 2002, pp.298-319.

NAscimento, Cecília V. do. O Sexo Feminino em Campanha pela emancipação da mulher (1873-1874). Dissertação de mestrado, Educação, UFMG, 2004.

NASCIMENTO, Kelly C. Entre a mulher ideal e a mulher moderna: representações femininas na imprensa mineira - 1873-1932. Dissertação de mestrado, História, UFMG, 2006.

OliveirA, Anelda P. de. Mulher fim-de-século, as representações sociais da mulher através da imprensa. Dissertação de mestrado, História, UFRGS, 2000.

PERROT, Michelle. As mulheres ou os silêncios da história. Bauru-SP, EDUSC, 2005.

SchwARCZ, Lilia. As barbas do Imperador. D. Pedro II, um monarca nos trópicos. São Paulo, Companhia das Letras, 1999.

SILVA, Thiago F. S. e. Mulheres goianas em ação: práticas abolicionistas, práticas políticas (1870-1888). Dissertação de mestrado, História, UnB, 2005.

VASCONCELLOS, Eliane. Beatriz Francisca de Assis Brandão. In: MUZART, Zahidé Lupinacci. (org.) Escritoras brasileiras do século XIX. Antologia. Volume I. Florianópolis, Editora Mulheres, EdUNISC, 2000, pp.82-109. 
Leitura e escrita femininas no século XIX

VillaltA, Luiz Carlos. O que fala e o que se lê. Língua, instrução e leitura. In: SoUZA, Laura de Mello. (org.) História da vida privada no Brasil. Cotidiano e vida privada na América Portuguesa. São Paulo, Companhia das Letras, 1997, vol. 1, pp.331-385.

VILLELA, Heloisa. O mestre-escola e a professora. In: LOPES, Eliane Marte T. S.; FARIA FILHO, Luciano M. De; VEIGA, Cynthia G. (orgs.) 500 anos de Educação no Brasil. Belo Horizonte, Autêntica, 2000, pp.95-134.

WATTS, Ruth. "Suggestive Books": the role of the writings of Mary Somerville in science and gender history. Paedagogica Historica, vol. 38, n 1, London - UK, Taylor \& Francis Group, 2002, pp.162-186.

\section{Periódicos consultados}

Astréa. Rio de Janeiro, Typographia da Astréa, 1826-1832.

Aurora Fluminense. Rio de Janeiro, Typografia de Gueffier, 1827-1839.

Espelho Diamantino (O). Rio de Janeiro, Imperial Typographia de P. Plancher-Seignot, 1827-1828.

Farol Paulistano (O). São Paulo, Imprensa de Roa e C., 1827-?

Manual das Brasileiras. São Paulo, s.d.

Mentor das Brasileiras (O). São João del-Rei, Typographia do Astro de Minas, 1829-1832.

Popular (O). Pernambuco, Typografia do Diário, 1830-1831.

Tribuno do Povo (O). Rio de Janeiro, Typographia da Astréa, 1830-?

Universal (O), Ouro Preto, Officina Patrícia de Barboza \& C., 1825-1842.

\section{Outras fontes impressas}

FENELON. Aventures de Télémaque. Texte établi d'aprés les manuscrits authentiques et publié avec une introduction et des notes par Albert Cahen. Paris, Librairie Hachette, 1920.

Projectos d'Estatutos para a Organização da Sociedade Phylopolytechnica emprehendida em a Villa de São João D'El Rei. Revista do Archivo Publico Mineiro. Belo Horizonte, Ano IV, 1899. 